\title{
Analytical Model for Concrete Jacketed RC Columns with Precorrosion and Postcorrosion Damages Under Uniaxial Loading
}

\author{
D. W. Zhang, Y. X. Zhao, S. J. Shen, and W. L. Jin \\ Institute of Structural Engineering, Zhejiang University \\ T. Ueda \\ Laboratory of Engineering for Maintenance System, Hokkaido University
}

\begin{abstract}
The main objective of this study is to investigate the effect of precorrosion and postcorrosion damage on concrete jacketed RC columns under uniaxial loading and to develop a rational methodology for predicting the corresponding compressive strength. The predamage and postdamage involved an electrochemical process to accelerate the migration of chlorides from an external electrolyte into the tested columns and a wetting-drying cycle process with a controlled current to speed up the corrosion of the reinforcing steel bars in the tested columns. An uniaxial loading test was to determine the structural performance of the concrete jacketed columns with or without corrosion damage. The failure mode, load-displacement, and load-strain responses of test columns were recorded, and the related mechanisms were discussed. Then a model that is capable of evaluating peak load of unjacketed or jacketed RC columns with or without corrosion damage was developed. The analytical approach considered the effect of reinforcement corrosion on the effective load-bearing area of concrete and the confinement effect from the web reinforcement. The analytical results agreed well with the experimental results, indicating the reliability and effectiveness of developed models.
\end{abstract}

\section{INTRODUCTION}

Reinforced concrete columns prior to and after retrofitting are often susceptible to various kinds of environmental and mechanical impacts; thus the material as well as structural performances deteriorate. Reinforcement corrosion is one of the major causes of deterioration in reinforced concrete columns. Past experience (Tang \& Nilsson, 1993; Zhao Lin, Wu, \& Jin, 2013) has shown that reinforcement corrosion not only reduces member strength due to steel area loss but also the primary mechanism of the bond strength between deformed bars and concrete deteriorate as well. Since the stirrups are near the exposed lateral surface, they are the first to be affected by corrosion. The section loss is more serious for the web reinforcement as it is usually fabricated from small diameter bars. Thus, its contribution to confinement decreases. Moreover, cover cracking and delamination expose the longitudinal reinforcement to further deterioration.

Extensive investigations on retrofitting of reinforced concrete columns have been undertaken in recent years, and many retrofitting methods have been developed and reported in the literatures $(\mathrm{Wu}, \mathrm{Liu}$, \& Oehlers, 2006). The commonly used methods usually involve the application of an additional layer of reinforced concrete, steel plate, or other materials such as fiber reinforce polymers (FRPs) onto the external face of an existing RC column. Reinforced concrete jacketing has been widely used since the last two decades of the twentieth century. Experimental results on the effectiveness of the technique are abundant for RC columns (Julio et al., 2003). The additional concrete and reinforcement layer, which generates an additional closed hoop, is generally effective in enhancing the shear strength, the flexural deformability of plastic hinge, and the bond between longitudinal reinforcement and concrete. The dilation/expansion of the concrete mobilizes the hoop resistance of the web reinforcement in substrate and jacketing, which in turn, provides passive confinement to the concrete inside. Despite the fact that FRP jacketing is gaining more and more interest recently, concrete jacketing is still in wide use mainly owing to its being less costly and easy for execution.

The corrosion damages can take effect throughout the whole service life of RC columns, including the prejacketing and postjacketing stages. Service life prediction with jacketing will only become realistic when predamage and postdamage caused by corrosion are taken into consideration. There are 
vast experimental researches relating to the effect of predamages or postdamages on the structural performance of concrete jacketed RC columns. In most of the previous studies, the predamages or postdamages were introduced by purely mechanical impact (Alcocer, 1993; Rodriguez \& Park, 1994; Stoppenhagen et al., 1995), while the damages with rebar corrosion before and after jacketing are less considered. Nevertheless, there is no existing model for predicting structural performance of concrete jacketed columns considering the degree of reinforcement corrosion as variables. The authors are conducting a series of studies on the structural performance of concrete jacketed columns with precorrosion and postcorrosion damages. In this paper, the effect of important parameters of predamage and postdamage, such as corrosion degree of web and longitudinal reinforcement in both jacketing layer and substrate, on the uniaxial loading performance of $\mathrm{RC}$ columns is studied experimentally in a systematic way. An analytical model was then developed considering the effect of reinforcement corrosion and confinement from web reinforcement. Finally, based on the proposed model, parametric studies were conducted to investigate the effect of various degrees of corrosion of jacketing or substrate reinforcement on the compressive strength of concrete jacketed RC columns. Some implications for a better structural performance were then raised.

\section{TEST PROGRAM}

\subsection{Specimen configuration and material property}

Table 1 summarizes the experimental program. In total, 14 columns were tested. All have the same substrate geometry and reinforcement. The acronym designation adopted for specimens was as follows: " $\mathrm{C}$ " represents column and the first number following " $\mathrm{C}$ " means designed corrosion degree of rebar in the substrate column; " $S$ " stands for jacketing; the second number indicates the designed corrosion degree of rebar in the jacketing. For example, specimen "C-5-S-10" is the jacketing jacketed column with designed corrosion degree of 5 and $10 \%$ of the rebar in the substrate and jacketing, respectively. The longitudinal and web reinforcement in the same section (jacketing or substrate) are set to reach the same corrosion degree.

Figure 1a shows the geometry and reinforcement details of the substrate columns. The substrate columns had a cross-section of $150 \mathrm{~mm} \times 150 \mathrm{~mm}$. The total height of the columns was $1000 \mathrm{~mm}$. For longitudinal reinforcement, the columns were reinforced with four $\varphi$ 12-mm deformed bars. About $\varphi$ 8-mm diameter smooth steel bars were provided as web reinforcement spaced at $150 \mathrm{~mm}$. The jacketed columns had a
Table 1. Basic experiment parameters.

\begin{tabular}{lccc}
\hline Spe. num. & $\begin{array}{c}\text { Concrete } \\
\text { jacketing }\end{array}$ & $\begin{array}{c}\text { Corrosion } \\
\text { degree of rebar } \\
\text { in substrate (\%) }\end{array}$ & $\begin{array}{c}\text { Corrosion } \\
\text { degree of rebar } \\
\text { in jacketing (\%) }\end{array}$ \\
\hline C-0 & No & 0 & - \\
C-0-S & Yes & 0 & 0 \\
\hline C-5 & No & 5 & - \\
C-5-S & Yes & 5 & 0 \\
C-5-S-5 & Yes & 5 & 5 \\
C-5-S-10 & Yes & 5 & 10 \\
C-5-S-15 & Yes & 5 & 15 \\
C-5-S-20 & Yes & 5 & 20 \\
\hline C-10 & No & 10 & - \\
C-10-S & Yes & 10 & 0 \\
C-10-S-5 & Yes & 10 & 5 \\
C-10-S-10 & Yes & 10 & 10 \\
C-10-S-15 & Yes & 10 & 15 \\
C-10-S-20 & Yes & 10 & 20 \\
\hline
\end{tabular}

Targeted corrosion area

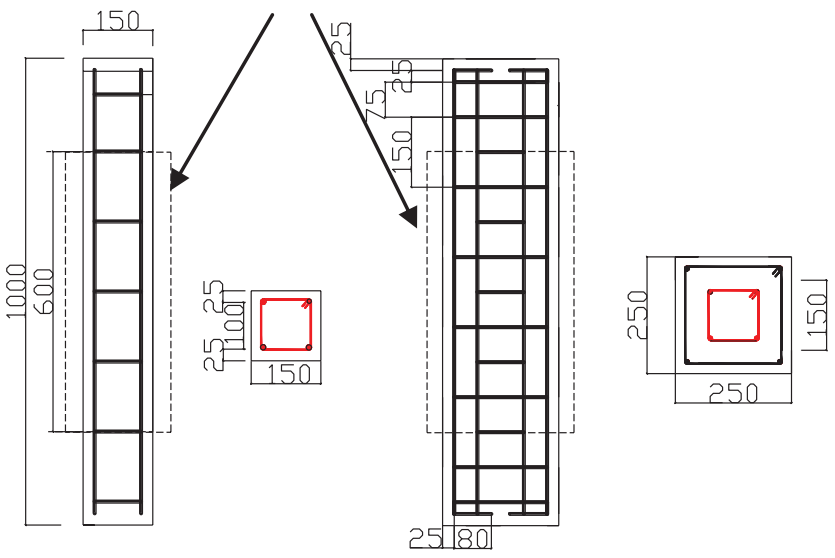

Figure 1. Geometry and reinforcement details of the tested specimens.

square cross-section of $250 \mathrm{~mm}$ wide as shown in Figure $1 \mathrm{~b}$. Similar to those of substrate columns, there were four $\varphi 12$ deformed longitudinal reinforcements, and the $\varphi 8 \mathrm{~mm}$ web reinforcements were arranged at $150-\mathrm{mm}$ intervals. The clear interval between internal and external web reinforcement was set to be $75 \mathrm{~mm}$. As shown in Figure 1, the specimens were corroded within $600 \mathrm{~mm}$ of the central column. The concrete cover thickness was the same for substrate and jacketing layer as $25 \mathrm{~mm}$. The 28-day compressive strength of substrate and jacketing concrete was determined as 36.7 and $38.2 \mathrm{MPa}$, respectively. The yield strength was 349 and $318 \mathrm{MPa}$ for the longitudinal and web reinforcements, respectively.

\subsection{Accelerated corrosion techniques}

Accelerated corrosion technique was applied in the laboratory to induce corrosion in a reasonable time frame, before and after concrete jacketing. Figure 2 


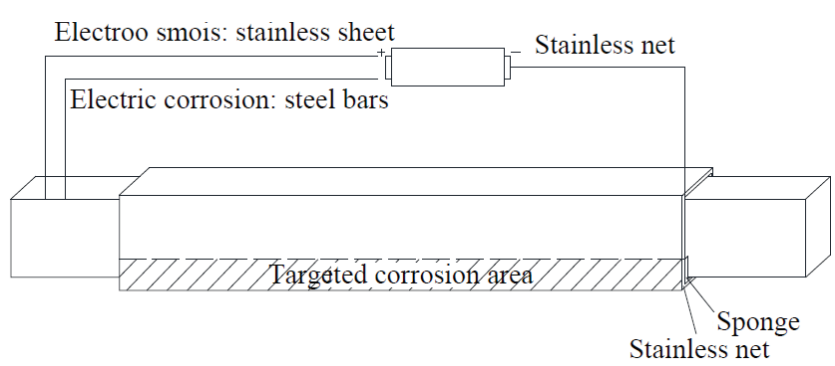

Figure 2. Accelerated corrosion techniques.

shows a schematic representation of the test setup for the accelerated corrosion. Sponge that soaks up $\mathrm{NaCl}$ solution was used to keep the concrete in the two targeted corrosion areas wet. Stainless steel nets were attached to the sponge. The outside of the column was then wrapped with a plastic sheet to keep the moisture in the sponge. The corrosion procedure can be divided into two phases, namely, the electromigration phase and the wetting-drying cycle phase. In the electromigration phase, chloride ions were electromigrated into concrete cover by means of using an electrochemical method. To simulate the realistic chloride ingress in concrete, $\mathrm{NaCl}$ solution of concentration $2 \mathrm{~mol} / \mathrm{L}$ was first put in the sponge to make the concrete wet for more than $24 \mathrm{~h}$. A hollow stainless steel bar was placed close to the neutral axis of the beam to act as a cathode terminal, while the tension reinforcement acted as an anode terminal. The estimated time for corrosion was calculated based on Faraday's law with a specified current density impressed through the steel reinforcement; a current density of $0.30 \mathrm{~A} / \mathrm{cm}^{2}$ was used in the current study to avoid the damaging influence of high current on the steel and concrete interfacial bond. After jacketing, the electromigration phase was stopped for the substrate reinforcement and only applied to the jacketing reinforcement. The procedure lasted for $3.5,7,10.5$, and 14 weeks for expected corrosion degree of $5,10,15$, and $20 \%$, respectively. A wetting-drying cycle process was used immediately after the electromigration process. Each cycle of the wetting-drying process involved 3 days drying followed by 4 days wetting. The drying process was achieved by taking off the plastic sheet to dry the sponge, whereas in the wetting process, the plastic sheet was reapplied to cover over the beam and $5 \% \mathrm{NaCl}$ solution was put in the sponge to make the concrete moisture. After the reinforcing steel of substrate column was corroded to the desired loss, the concrete jacketing was added.

\subsection{Reinforced concrete jacketing scheme}

According to CECS:25 (1990), for specimens with 5\% expected corrosion degree, the surface deficiencies were removed until the dense concrete was exposed, then the concrete was chipped to form a slot that was
$10 \mathrm{~mm}$ deep, and at $80-\mathrm{mm}$ intervals. The concrete corner was rounded, and the dust was cleaned. For specimens with $10 \%$ expected corrosion degree, the cover concrete cracked owing to corrosion expansion being chipped away until the dense concrete was exposed. Before the concrete jacketing, the substrate surface was cleaned with water and a thin mortar layer was sprayed onto the concrete surface to enhance the bond between old and new concrete. The substrate column and the jacketing reinforcement were put into a wooden mold and fixed well. The jacketing concrete was then casted into the wooden mold with sufficient vibration to ensure the quality of jacketing.

\subsection{Test setup and instrumentation}

All the specimens were tested under monotonic axial load till the peak load at a rate of loading of $20 \mathrm{kN} / \mathrm{min}$ for unjacketed columns and $40 \mathrm{kN} / \mathrm{min}$ for jacketed columns. As shown in Figure 3, two steel plates were placed at the top and bottom specimen surface to distribute the axial stress. Four linear variable differential transformers (LVDTs) were used to measure the vertical displacements at the loading point. Several strain gages were used at the center of four specimen sides to measure the vertical and transverse strain responses of surface concrete. The crack pattern, the load-displacement, and loadstrain responses were recorded.

\section{RESULTS AND DISCUSSION}

\subsection{Gravimetric mass loss measurements}

The weight of the steel reinforcing bars before corrosion was determined, so that the weight of the extracted coupons after corrosion can be compared with the original weight and the mass loss due to corrosion can be estimated. After loading the test

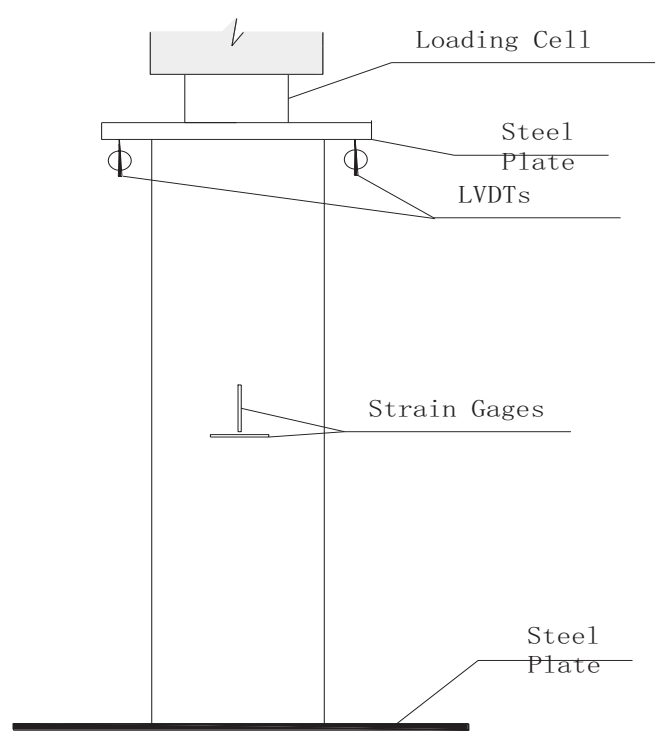

Figure 3. Illustration of loading system. 
Table 2. Comparison between calculated and experimental peak load.

\begin{tabular}{|c|c|c|c|c|c|c|c|c|}
\hline \multirow[t]{2}{*}{ Spe. num } & \multicolumn{2}{|c|}{$\begin{array}{c}\text { Corrosion degree of } \\
\text { substrate reinforcement } \\
(\%)\end{array}$} & \multicolumn{2}{|c|}{$\begin{array}{c}\text { Corrosion degree of } \\
\text { jacketing reinforcement } \\
(\%)\end{array}$} & \multirow[t]{2}{*}{$\begin{array}{l}\text { Experimental } \\
\text { peak load } P_{\text {exp }} \\
(\mathrm{kN})\end{array}$} & \multirow[t]{2}{*}{$\begin{array}{l}\text { Coordinate } x \\
(\mathrm{~mm})\end{array}$} & \multirow[t]{2}{*}{$\begin{array}{c}\text { Calculated } \\
\text { peak load } \\
P_{\text {ana }}(k N)\end{array}$} & \multirow[t]{2}{*}{$\frac{P_{\text {ana }}}{P_{\text {exp }}}$} \\
\hline & Longitudinal & Web & Longitudinal & Web & & & & \\
\hline C-0 & 0 & 0 & - & - & 654 & 0 & 787 & 1.20 \\
\hline C-0-S & 0 & 0 & 0 & 0 & 1790 & 47 & 1816 & 1.01 \\
\hline C-5 & 7.26 & 8.18 & - & - & 564 & - & 539 & 0.96 \\
\hline C-5-S & 6.50 & 7.10 & 0 & 0 & 1589 & 48 & 1793 & 1.13 \\
\hline C-5-S-5 & 6.02 & 6.62 & 5.16 & 6.09 & 1569 & 48 & 1576 & 1.00 \\
\hline C-5-S-10 & 9.07 & 7.97 & 12.22 & 13.52 & 1397.5 & 48 & 1225 & 0.88 \\
\hline C-5-S-15 & 6.45 & 4.82 & 13.69 & 13.03 & 1223 & 47 & 1231 & 1.01 \\
\hline C-5-S-20 & 7.18 & 6.17 & 18.21 & 18.00 & 1048.5 & 47 & 1214 & 1.16 \\
\hline C-10 & 18.75 & 15.21 & - & - & 247 & 0 & 375 & 1.52 \\
\hline C-10-S & 14.57 & 17.33 & 0 & 0 & 1693.5 & 51 & 1764 & 1.04 \\
\hline C-10-S-5 & 15.64 & 16.48 & 6.25 & 8.45 & 1460 & 50 & 1478 & 1.01 \\
\hline C-10-S-10 & 15.58 & 16.61 & 9.91 & 16.86 & 1285.5 & 49 & 1272 & 0.99 \\
\hline C-10-S-15 & 11.07 & 14.44 & 19.49 & 18.97 & 1283 & 48 & 1195 & 0.93 \\
\hline C-10-S-20 & 14.49 & 13.76 & 25.83 & 22.78 & 921.5 & 48 & 1166 & 1.27 \\
\hline
\end{tabular}

specimens to failure, the specimens were crushed, and longitudinal and web steel bars were taken out for the purpose of mass loss calculation. The average measured values for the mass loss (corrosion degree) in the steel of the corroded beams were listed in Table 2. It can be concluded that the expected mass losses were achieved and a nonuniform corrosion of steel bars was realized in the laboratory.

\subsection{Strain development and failure mode}

The load-strain relations at the center of loaded specimens were shown in Figure 4. The positive value is the horizontal strain and the negative value is the longitudinal strain.

For unjacketed specimens (C-0, C-5, C-10), the longitudinal strain at the peak load decreased with the increasing of corrosion degree. The corresponding jacketed specimens (C-0-S, C-5-S, C-10-S) had a similar peak longitudinal strain, indicating that the jacketing technique can compensate the precorrosion effect of substrate reinforcement. The horizontal peak strain of unjacketed and jacketed specimens were similar except for specimen C-10, which may result from the data scatter. For uncorroded (C-0, C-0-S) or light-corroded (C-5, C-5-S, C-5-S-5, C-10-S, C-10-S-5) columns, the strain developed linearly at the early loading stage and increased fast at the later stage.

For $\mathrm{C}-5$ and $\mathrm{C}-10$ series, the longitudinal strain at the peak load decreased with the increasing of corrosion degree, while the horizontal strain showed no clear tendency.

For uncorroded columns with or without jacketing, the failure procedure can be roughly divided into three stages, which are the initial elastic stage, the in-between

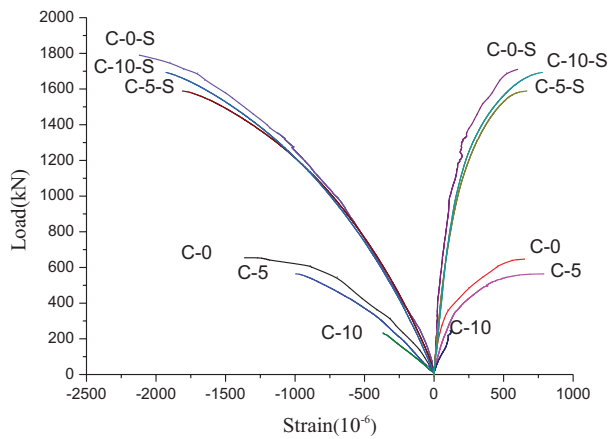

(a)

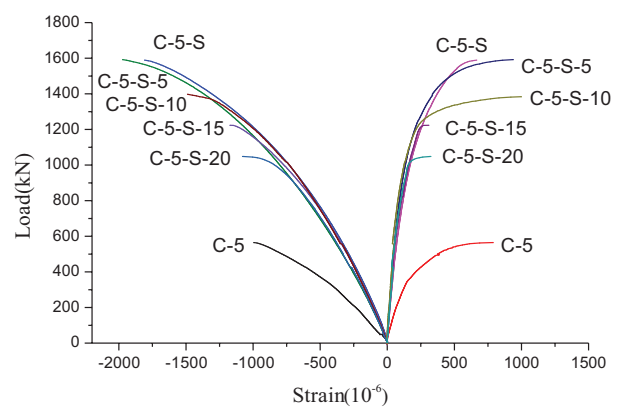

(b)

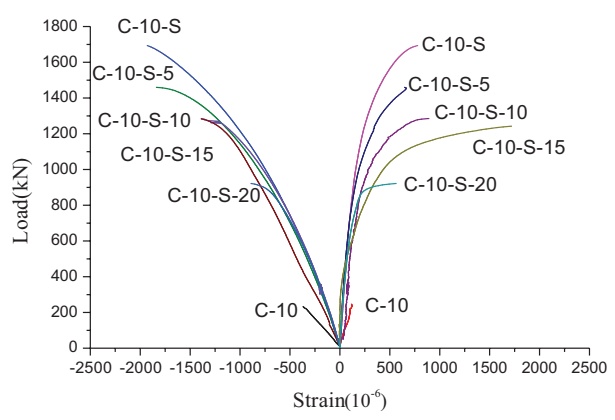

(c)

Figure 4. Load-strain relation of tested specimens. (a) comparing before and after jacketing. (b) C-5 seires. (c) C-10 seires. 
elastic-plastic stage, and the final failure stage. At the first stage, concrete carried the entire load and only few cracks were generated. With the increasing of load, the load was carried by both concrete and longitudinal reinforcements. Due to the end effect, some cracks can be observed at the two edges of columns and tended to propagate toward the center. The final failure stage was initiated after the yielding of longitudinal reinforcement. The concrete cracks drastically increased in both quantity and width. The final failure was brittle failure with crushing of concrete after buckling of longitudinal reinforcement, whereas the web reinforcement did not break. The failure location of $\mathrm{C}-0$ is near to the column bottom and that of $\mathrm{C}-0-\mathrm{S}$ is near to the column top, leading to the end effect.

The failure mode of corroded columns with or without jacketing depended on the corrosion degree of rebar and the bond between rebar and concrete. In case of light corrosion with corrosion degree about $5 \%$, the column failure mode was similar to that of the uncorroded one. For heavy corrosion with corrosion degree greater than $10 \%$, cracks developed at the small load level along the length and width of the longitudinal concrete, some of the cover concrete was spalling due to corrosive expansion, and the load was mainly carried by the core concrete. With the further increasing of applied load, the stress of corroded longitudinal reinforcement increased rapidly and reached the yielding status. The confinement from web reinforcement was weakened as well, leading to the corrosion effect and the web reinforcement broke at the final failure stage. The failure was located mostly within the targeted corrosion area. For all the jacketed columns, there was no delamination between the substrate and the jacketing concrete until the final failure; the substrate and the jacketing layer behaved monolithically. Figure 5 showed the typical failure of specimens C-0-S and C-10-S-15.

\subsection{Peak load and displacement}

The recorded peak load and corresponding displacements were listed in Table 2, and the loaddisplacement curves were shown in Figure 6 . The peak load and stiffness of the jacketed columns were enhanced compared with the control unjacketed columns. The peak load of C-0-S, C-5-S, and C-10-S were increased by 274,248 , and $627 \%$ that of $\mathrm{C}-0$, C-5, and C-10, respectively, showing the effectiveness of the jacketing technique. For unjacketed columns, the stiffness and peak load decreased with increment of corrosion degree. The peak loads of specimens C-5 and C-10 were 86 and $38 \%$ that of specimen C-0, respectively, while after jacketing, the specimens C-0-S, C-5-S, and C-10-S had peak loads of 1790 , 1589 , and $1693 \mathrm{kN}$, respectively, showing that the effect of corrosion in the substrate reinforcement was weakened after concrete jacketing. This led to two

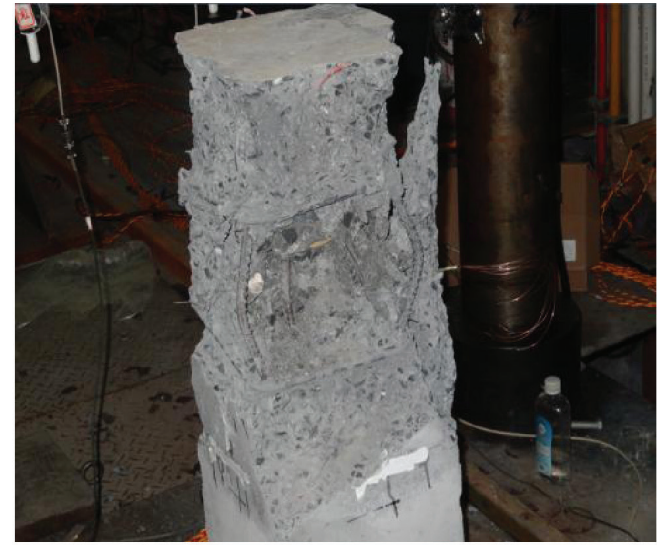

(a). C-0-S

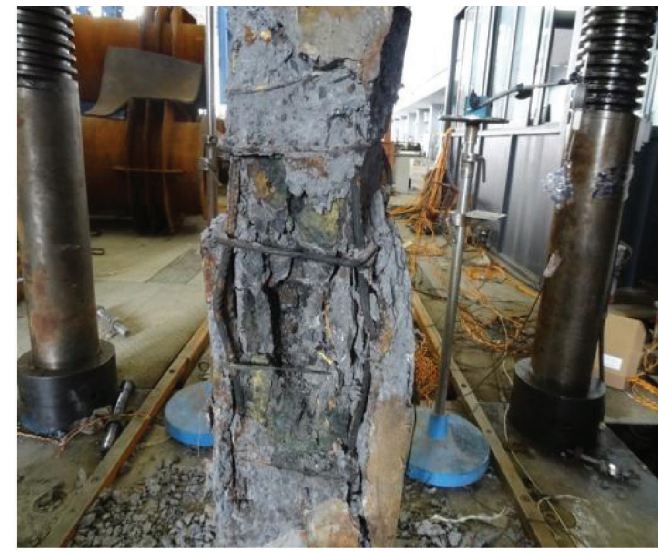

(b).

C-10-S-15

Figure 5. Sample typical failure of tested specimen.

consequences: one, the increase of cross-sectional area and external reinforcement after jacketing weakened the contribution of substrate column to the peak load, and two, for severe corroded substrate, the concrete loosened or cracked after reinforcement corrosion was removed and new fresh concrete was added, which reduced the effect of substrate concrete loss due to reinforcement corrosion.

Figure 7 showed the effect of longitudinal or web rebar corrosion in jacketing layer on the peak load of tested specimens ( $\mathrm{C}-5$ and $\mathrm{C}-10$ series). The corrosion of reinforcement in the jacketing layer showed distinct effect to the peak load of jacketed columns. With increasing of corrosion degree of jacketing reinforcement, the peak load of C-5 series reduced $1.3,12.1,23.0$, and $34.0 \%$, respectively; the peak load of C-10 series reduced 13.8, 24.1, 24.2, and $45.6 \%$, respectively. The peak load of C-10-S-20 was reduced almost to half of the corresponding uncorroded specimen $\mathrm{C}-10-\mathrm{S}$. The $\mathrm{C}-10$ series decreased more since the actual corrosion degree was higher than that of the $\mathrm{C}-5$ series. The corrosion of longitudinal and web reinforcement in the jacketing caused deterioration of bond between concrete and 


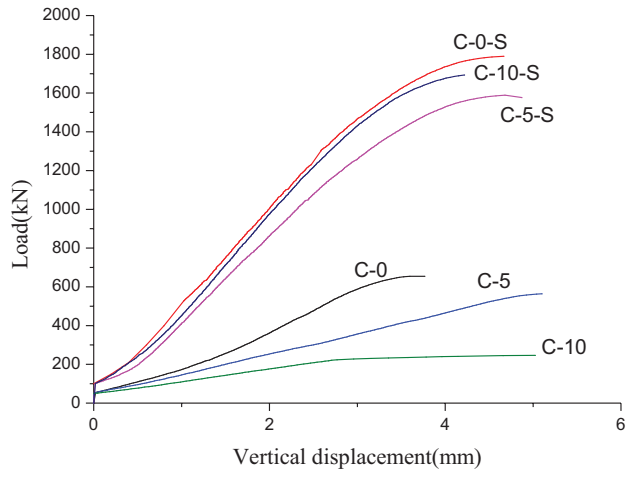

(a)

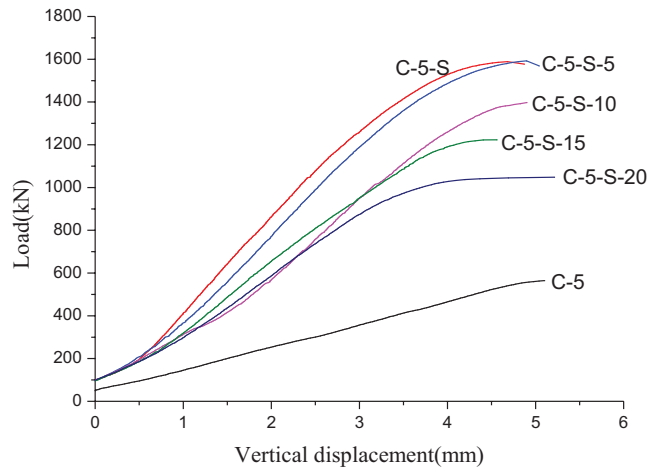

(b)

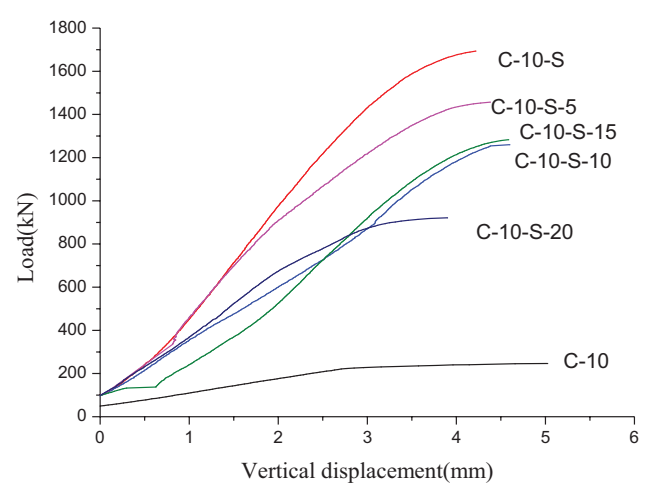

(c)

Figure 6. Load-displacement curves of test specimens. (a) Comparing before and after jacketing. (b) C-5 series. (c) C-10 series.

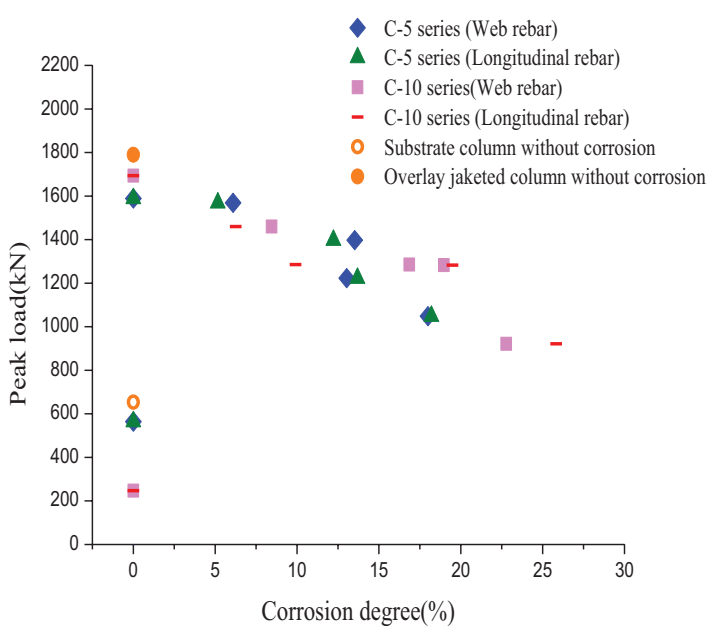

Figure 7. Effect of rebar corrosion on the peak load of tested specimen.

reinforcement and the external concrete cracking, which reduced the effective concrete area for load bearing. Meanwhile, the mechanical properties of reinforcement were degraded so that the contribution of longitudinal reinforcement to the axial loading and the web reinforcement to the core concrete confinement was weakened.

The displacement at peak load of the C- 5 series was all about $5 \mathrm{~mm}$ and that of the C-10 series was all around $4.5 \mathrm{~mm}$, indicating that the reinforcement corrosion after jacketing had insignificant effect on this displacement. At the peak load, the specimen C-10-S-20 with a real corrosion degree of more than $22 \%$ of jacketing reinforcement had a displacement of about $3.9 \mathrm{~mm}$. This led to the severe corrosion damage of jacketing web reinforcement, which greatly reduced its confinement effect and resulted in an early brittle failure with concrete crushing.

\section{ANALYTICAL MODEL}

Based on the experimental results, the compressive strength of columns was greatly affected by the severe corrosion damage. To predict the compressive strength of unjacketed or jacketed RC columns with or without corrosion damage in either substrate or jacketing layer, the effect of corrosion should be considered based on the current design models for RC columns without corrosion effect. An analytical model is then proposed to verify test results and to predict the strength of uniaxial loaded corroded RC columns with or without concrete jacketing.

\subsection{Confinement from web reinforcement}

As shown in Figure 8, for a RC column without concrete jacketing, the confined compressive strength 


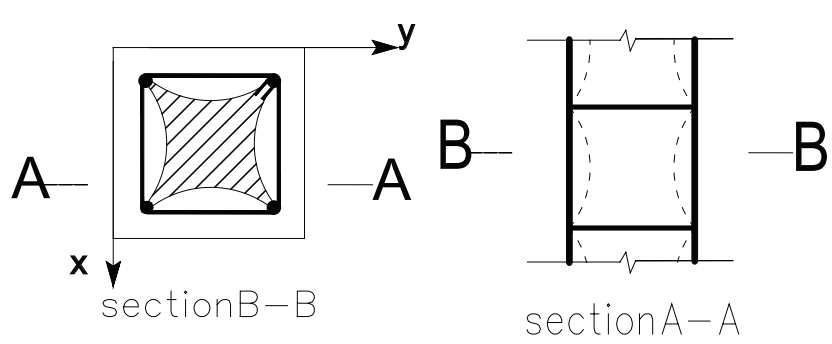

Figure 8. Cross-section of substrate column.

of concrete $\left(f^{\prime} c c\right)$ with the web reinforcements can be calculated according to Mander, Priestley, and Park (1988) as

$$
f_{c c}^{\prime}=f_{c 0}\left(-1.254+2.254 \sqrt{1+\frac{7.94 f_{l}^{\prime}}{f_{c 0}}}-2 \frac{f_{I}^{\prime}}{f_{c 0}}\right),
$$

where $f_{c 0}=$ the compressive strength of unconfined concrete and $f_{1}^{\prime}=$ the effective lateral confining stress on the concrete. For a square concrete cross-section with symmetrical arrangement of reinforcements as in this study, $f$, can be calculated as

$$
\begin{aligned}
f_{l}^{\prime} & =\frac{A_{s V}}{s a_{c}} f_{y h} \frac{A_{e}}{A_{c c}} \\
& =\frac{A_{s V}}{s a_{c}} f_{y h}\left(a_{c}^{2}-\frac{2 w^{2}}{3}\right)\left(1-\frac{s^{\prime}}{2 a_{c}}\right)^{2} /\left(a_{c}^{2}-A_{s}\right)^{\prime}
\end{aligned}
$$

where $A_{\mathrm{sv}}=$ the cross-sectional area of unit web reinforcement; $A_{\mathrm{e}}$ and $A_{\mathrm{cc}}$ are effective confining area and core area of concrete enclosed by the centerlines of perimeter web reinforcement, respectively; $A_{\mathrm{s}}=$ area of longitudinal reinforcement enclosed by web reinforcement; $a_{c}=$ core dimension to centerlines of perimeter web reinforcement $=$ center-to-center spacing of web reinforcement; $s^{\prime}=$ clear vertical spacing between web reinforcement; $f_{\text {yh }}=$ yielding strength of web reinforcement; $w$ = clear distance between adjacent longitudinal bars.

For a jacketed RC column, the confinement effect on the core concrete varies due to the arrangement of both internal and external reinforcements. As shown in Figure 9, based on the reinforcement arrangement, the jacketed concrete cross-section is divided into four sections, namely, I, II, III, and IV. Sections I and II are both unconfined area, while Section I is defined to consider the rebar corrosion effect. Section III is confined by the jacketing reinforcement, and Section IV is confined by both substrate and jacketing reinforcement. The uniaxial loading capacity of jacketed RC column is then the accumulation of compressive strength of four concrete sections together with the internal and external longitudinal reinforcements as follows:

$$
\begin{aligned}
F & =\phi\left(F_{I}+F_{I I}+f_{y o} A_{s o}\right)+F_{I I I}+F_{I V}+f_{y i} A_{s i} \\
& =\phi\left(f_{c 0}\left(A_{I}+A_{I I}\right)+f_{y 1} A_{1}\right)+f_{c 1} A_{I I I}+f_{c 2} A_{I V}+f_{y 2} A_{2}
\end{aligned}
$$

where $F_{\mid,}, F_{\|}, F_{1 \mid,}, F_{\mathrm{IV}}=$ concrete compression capacity of Sections I, II,III, and IV, respectively; $A_{\|}, A_{\|}$, $A_{\mathrm{III}}, A_{\mathrm{IV}}=$ concrete area of Sections I, II, III, and IV, respectively; $\varphi=$ reduction coefficient considering the nonsynchronous response between jacketing and substrate sections $=0.80$ (CECS:25 1990); $f_{\mathrm{yi}}$ and $f_{\mathrm{yo}}=$ yielding strength of substrate and jacketing longitudinal reinforcement, respectively; $A_{\mathrm{yi}}$ and $A_{\mathrm{yo}}=$ total cross-sectional area of substrate and jacketing longitudinal reinforcement, respectively; $f_{\mathrm{c} 1}, f_{\mathrm{c} 2}=$ confined concrete compressive strength in Sections III and IV, respectively.

For concrete jacketed RC column, the area of ineffectively confined concrete core between adjacent web reinforcements depends on the geometrical arrangement of both jacketing and substrate web reinforcements. As shown in Figure 9, the web reinforcements in jacketing and substrate are arranged interlaced with the same intervals. With the given coordinate system, the ineffectively confined concrete core area in the jacketing and substrate is

$$
\begin{gathered}
A_{\mathrm{eo}}(x)=\left(a_{\mathrm{co}}^{2}-\frac{2 w_{\mathrm{o}}^{2}}{3}\right)\left(1-\frac{2}{a_{c o}}\left(x-\frac{x^{2}}{s_{\mathrm{o}}^{\prime}}\right)\right)^{2} \\
A_{e i}(x)=\left(a_{c i}^{2}-\frac{2 w_{i}^{2}}{3}\right)\left(1-\frac{2}{a_{c i}}\left(\frac{s_{i}^{\prime}}{4}-\frac{x^{2}}{s_{i}^{\prime}}\right)\right)^{2}
\end{gathered}
$$

where $a_{\mathrm{co}}, a_{\mathrm{ci}}=$ core dimension to centerlines of perimeter web reinforcement in jacketing and substrate, respectively; $s_{0}^{\prime}, s_{i}^{\prime}=$ clear vertical spacing between web reinforcement in jacketing and substrate, respectively; $w_{\mathrm{o}}, w_{\mathrm{i}}=$ clear distance between adjacent longitudinal bars in jacketing and substrate, respectively. The coordinate $x$ corresponding to the maximum ineffectively confined concrete core
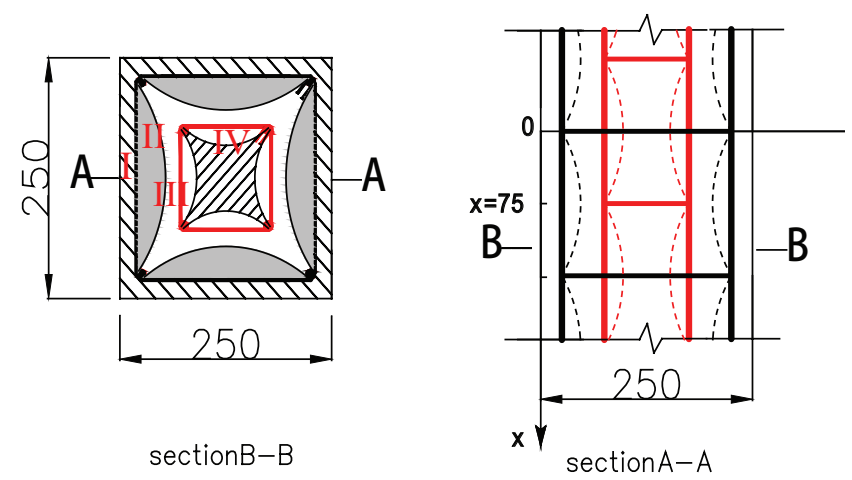

Figure 9. Cross-section of jacketed column. 
area can be determined by the following differential equation:

$$
\frac{d F(x)}{d x}=0
$$

\subsection{Effect of rebar corrosion}

The rebar corrosion decreased the rebar crosssectional area and its yielding strength. According to Xia (2010), for the RC column with rebar corrosion under accelerated corrosion method, the yielding strength of longitudinal reinforcement deteriorated with the increasing of its corrosion degree as the following equation:

$$
f_{y c}=f_{y}(-2.0986 \eta+1)
$$

where $f_{\mathrm{y}}$ and $f_{\mathrm{yc}}$ are the rebar yielding strength without corrosion and with average corrosion degree of $\eta$, respectively.

Meanwhile, the crack caused by the rust expansion reduced the effective area of concrete in compression. According to CECS:220 (2007), the reduced effective concrete dimension with longitudinal rebar corrosion is calculated as follows:

$$
\begin{gathered}
h_{c}=h-\alpha\left(c_{1}+c_{2}\right) \\
b_{c}=b-\alpha\left(c_{3}+c_{4}\right),
\end{gathered}
$$

where $h_{c}, b_{c}=$ concrete dimension with corrosion damage; $h, \bar{b}=$ concrete dimension without corrosion damage; $C_{1}, C_{2}, C_{3}, C_{4}=$ concrete cover thickness; $\alpha=$ reduction coefficient as a function of corrosion crack width along the corroded rebar, which can be determined based on Table 3.

The relation between corrosion degree and width of corrosion crack with deformed rebar can be reflected according to CECS:220 (2007) as:

$$
\omega=\left(\delta-0.008 c / d-0.00055 f_{\text {cuk }}-0.015\right) / 0.086,
$$

where $c=$ concrete cover thickness; $f_{\text {cuk }}=$ characteristic compressive strength of concrete. $\Delta=$ corrosion thickness of rebar, which is a function of corrosion degree as

$$
\delta=\frac{d}{2}(1-\sqrt{1-\eta})
$$

Table 3. Dimension reduction coefficient $\alpha$.

\begin{tabular}{lccc}
\hline \multirow{2}{*}{$\begin{array}{l}\text { doad } \\
\text { direction }\end{array}$} & \multicolumn{2}{c}{ Longitudinal crack width $(\omega)$ unit: $\mathbf{~ m m}$} \\
\cline { 2 - 4 } & $\mathbf{0 < \omega \leq \mathbf { 2 }}$ & $\mathbf{2}<\omega \leq \mathbf{3}$ & $\boldsymbol{\omega}>\mathbf{3}$ \\
\hline \multirow{3}{*}{$\begin{array}{l}\text { Uniaxial } \\
\text { compression }\end{array}$} & $\alpha=0.30 \omega$ & $\begin{array}{l}-(1-0.3 \omega) \\
(\omega-2)\end{array}$ & 1 \\
& &
\end{tabular}

where $d=$ diameter of rebar and $\eta=$ average corrosion degree.

For a RC column without concrete jacketing, the reduction of effective concrete area is mainly considered by reducing the concrete cover thickness, while for a jacketing jacketed RC column, the reduction of effective concrete area is mainly considered for the concrete cover in the jacketing (area I in Figure 9), and the area reduction from corrosion of substrate rebar can be ignored due to confinement from the jacketing reinforcement and the substrate treatment before applying jacketing.

Considering the yielding strength and its confinement effect as well as effective concrete area deterioration as the effect of rebar corrosion, the uniaxial compressive strength of the RC column with or without jacketing and rebar corrosion can be determined based on Equation (3).

\subsection{Verification}

The recorded experimental peak load is used for verifying the applicability of proposed analytical model. In this article, for control specimen, $h=b=$ $150 \mathrm{~mm}$, and for jacketed specimen, $h=b=250 \mathrm{~mm}$. $c_{1}=c_{2}=c_{3}=c_{4}=25 \mathrm{~mm}$. The analytical results of all the specimens with or without predamage and postdamage and their comparison with experimental records are shown in Table 2 and Figure 10, respectively. The maximum ineffectively confined concrete core was located at $x \approx 47 \mathrm{~mm}$, which existed between the web reinforcement in the substrate and the jacketing. The mean value of ratio of analytical and experimental compressive strength $P_{\text {ana }} / P_{\text {exp }}$ is 1.01 with standard deviation of 0.17 . The analytical values have a satisfactorily agreement with the experimental values, which verifies the accuracy of the proposed model, indicating that the proposed prediction method is applicable and reliable.

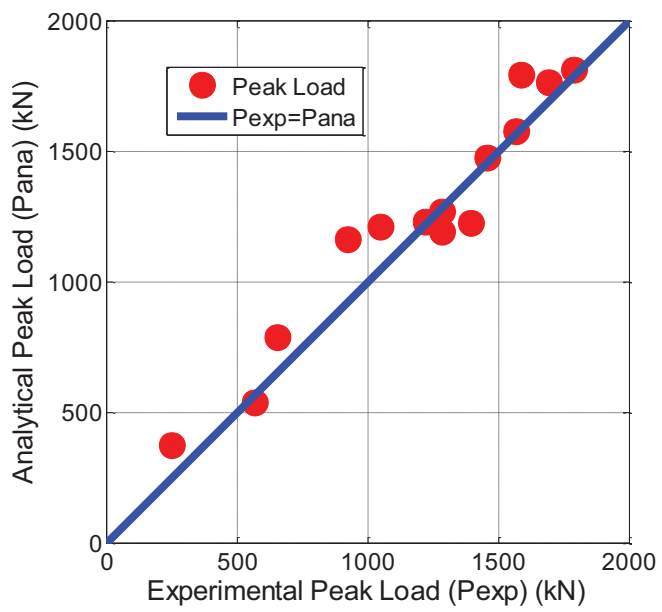

Figure 10. Comparison between calculated and experimental compressive strength. 


\section{CONCLUSIONS}

The precorrosion and postcorrosion damaged RC columns under uniaxial loading were examined in this article. Based on the research results, the following conclusions can be drawn:

- The failure mode of corroded columns with or without jacketing depended on the corrosion degree of reinforcement and the bond between reinforcement and concrete. In case of light corrosion, the column failure mode was concrete crushing without breakage of web reinforcement. For heavy corrosion with corrosion degree greater than $10 \%$, the longitudinal reinforcement yielded earlier and the web reinforcement was broken with crushing of the core concrete.

- With the longitudinal strain of concrete, the stiffness and compressive strength of column decreased with the increasing of corrosion degree. The corrosion of jacketing reinforcement had more pronounced effect on the compressive strength than the corrosion of substrate reinforcement. This led to the reduction of effective area of jacketing cover concrete and confinement from jacketing web reinforcement due to corrosion.

- The corrosion degree of jacketing reinforcement less than $20 \%$ had insignificant effect on the displacement at the peak load, while when the corrosion degree of jacketing reinforcement is more than $20 \%$, the displacement at the peak load decreased with early breaking of web reinforcement.

- An analytical model that can predict the strength of uniaxially loaded corroded RC columns with or without concrete jacketing was proposed. The analytical results agreed well with the experimental values.

- Parametric studies were conducted based on the proposed model. The longitudinal rebar corrosion has more distinct effect on the peak load than that of web rebar and the jacketing rebar corrosion has more distinct effect on the peak load than that of substrate rebar. Therefore more attention should be paid to restrain the longitudinal and jacketing rebar corrosion to guarantee the axial compression performance of jacketing jacketed $\mathrm{RC}$ column.

\section{ACKNOWLEDGMENTS}

The financial support from Science Technology Department of Zhejiang province (No. 2013C33041) and Ministry of Education of China with Grant No.NCET-12-0493 is greatly appreciated.

\section{REFERENCES}

CECS25:90. (1990). Design Code for strengthening concrete structure. China Association for Engineering Construction Standardization.

CECS 220. (2007). Standard for durability assessment of concrete structures. China Association for Engineering Construction Standardization.

Mander, J. B., Priestley, M. J. N., \& Park, R. (1988). Theoretical stress-strain model for confined concrete. Journal of Structural Engineering, ASCE, 114(8), 1804-1826.

Tang, L. P., \& Nilsson, L. O. (1993). Rapid determination of the chloride diffusivity in concrete by applying an electric field. ACI Material Journal, 89, 49-53.

Wu, Y. F., Liu, T., \& Oehlers, D. J. (2006). Fundamental principles that govern retrofitting of reinforced concrete columns by steel and FRP jacketing. Advances in Structural Engineering, 9(4), 507-533.

Xia, J. (2010). Mechanical investigations of corroded RC Members (PhD dissertation).

Zhao, Y. X., Lin, H. W., Wu, K., \& Jin, W. L. (2013). Bond behavior of normal/recycled concrete and corroded steel bars. Construction and Building Materials, 48, 348-359. 